\title{
AC 2009-199: CHASING THE POT OF GOLD
}

\section{Russel Jones, World Expertise LLC}

Russel Jones is Advisor to the Khalifa University of Science, Technology and Research in Abu Dhabi, UAE. He previously served as founding president of the Masdar Institute of Science and Technology in the UAE. His career in higher education in the United States included faculty member at MIT, department chair at Ohio State University, dean of engineering at University of Massachusetts-Amherst, academic vice president at Boston University, and President at University of Delaware. 


\title{
CHASING THE POT OF GOLD
}

\begin{abstract}
The oil-rich countries of the Middle East are investing heavily in education, utilizing income from oil sales to develop the human capacity to diversify their economies toward knowledge-based activities. American universities, seeking income to replace that lost by the exodus of many international students after 911 and desiring to have more international experience for their faculty and students, are responding by offering education programs of various types in the region.
\end{abstract}

\section{Introduction}

Several oil-rich countries in the Middle East, such as the United Arab Emirates, Oman, the Kingdom of Saudi Arabia, and Qatar) have come to understand that they must diversify their economies, utilizing significant amounts of the income from sale of their oil and gas at current high prices to invest in future commercial efforts. In particular, several such countries are focusing on developing "knowledge economies", by developing higher education programs that will provide the human capacity to initiate and support such new economic thrusts. Total spending by the Gulf Cooperation Council countries on education in 2008 exceeds their \$20-billion in arms purchases from the United States.

Many universities from North America, Europe and Australia have rushed to these oilrich countries to offer their services - for a price. Proposals for branch campuses, storefront programs, and partnerships abound. Many of the universities making proposals to the rulers of Middle East countries have solid programs to offer, but almost all of them see significant financial gain as a major driving force.

This paper explores the dimensions of the higher education scene in several Middle East countries, and suggests appropriate considerations for the involvement of foreign institutions there.

\section{Driving forces}

The oil-rich countries of the Middle East have come to recognize that their substantial incomes from the sale of oil and gas will have a finite lifetime, and that they should be investing some of today's income flow in economic diversification. The world wants to use less oil - both due to its cost, and due to the pollution of the environment which is leading to global warming. In addition, the oil supply in producing countries will run out someday, in many cases in less than 100 years. 
After the terrorist attacks on the United States on 911, the flow of Middle East students to the US for study reduced substantially. Potential students were concerned that their Muslim religion and Arabic culture would not be well received in the US, and student visa processes became lengthy and difficult. Middle East students who wanted to study abroad in English - a significant number - diverted from the US to other countries such as Canada, Australia and the United Kingdom. Among other impacts, such as less diversity in the student body, this has resulted in significantly less tuition income to many US universities.

Many US universities want to broaden their international activities, and the oil-rich countries are seeking ways to upgrade and expand their higher education programs. This has appropriately led to many partnerships, whereby US universities offer education in Middle East countries in a variety of formats.

\section{Seeking appropriate opportunities}

In an educational gold rush, US universities are seeking to set up outposts in developing countries with limited higher education opportunities and strong financial resources. The American system of higher education, long recognized as one of the best in the world, is thus becoming an important U.S. export.

One of the most visible recent connections between a US university and an oil-rich country in search of academic partnerships is that of New York University with the Abu Dhabi Emirate of the United Arab Emirates. According to a 2008 article in the New York Times $^{2}$ the President of New York University was approached by an investor trying to entice him to open a branch in the United Arab Emirates. Not sure what to make of the proposal, the President asked for a \$ 50-million donation to the University as earnest money - saying that he would then take the proposal seriously. As things developed, the money did materialize, from the government of Abu Dhabi.

NYU had long been committed to building its international presence, and had increased study-abroad sites to places such as Singapore, Accra and Buenos Aires. But the plan that has developed for a comprehensive, residential liberal-arts and sciences branch campus in the Arabian Gulf, set to open in 2010, is in a class by itself. The NYU/Abu Dhabi project will see a flow of professors and students between New York and Abu Dhabi, allowing seamless transfers.

The NYU/Abu Dhabi project thus meets several needs of the US university, and simultaneously addresses a major goal of Abu Dhabi, to be identified as a hub of knowledge transmission and creation in the region, as well as attending to the need to build human capacity in its citizens and its significant expatriate population. 


\section{US engineering programs in the Middle East}

Several US engineering schools have entered into partnerships with governments, or opened some version of a branch campus, to offer engineering education programs in the Middle East.

\section{Qatar}

In Qatar, the Qatar Foundation has established a major Education City in Doha which hosts branch campus programs of six major US universities ${ }^{3}$. The Qatar Foundation was established in 1995 by the country's ruler, with a multibillion-dollar endowment to fully finance universities that agreed to open branches there. ${ }^{4}$ Programs range from a medical school supported by Cornell University to a foreign service school offered by Georgetown University, with other programs by Virginia Commonwealth University and Northwestern University. Engineering programs are offered by Texas A\&M University and Carnegie Mellon University. Purpose built state-of-the-art learning and teaching facilities have been built for each university.

Texas A\&M University at Qatar offers undergraduate degrees in chemical, electrical, mechanical and petroleum engineering. It graduated two students in 2007 and a full class in 2008. It is beginning to offer two graduate programs, a Master of Engineering Degree and a Master of Science Degree. The undergraduate curriculum integrates cutting-edge and applied research with innovative classroom instruction to ensure that its graduates are equipped to assume leadership roles after graduation.

Carnegie Mellon Qatar has offered undergraduate programs in Computer Science and Business Administration since 2004. It has recently added a new Information Systems degree. These programs are aimed at providing the human capital to develop an effective Information and Computer Technology (ICT) structure, one of the main pillars of the knowledge-based society that Qatar aspires to become.

\section{Saudi Arabia}

King Abdullah University of Science and Technology (KAUST) is being built in Saudi Arabia as an international, graduate level research university dedicated to stimulating a new age of scientific achievement in the Kingdom ${ }^{5}$. The University is scheduled to open in September 2009 with degrees in 11 fields of study:

- Applied Mathematics and Computational Science

- Bioscience

- Chemical and Biological Engineering

- Chemical Science

- Computer Science

- Earth Science and Engineering

- Electrical Engineering 
- Environmental Science and Engineering

- Marine Science and Engineering

- Materials Science and Engineering

- Mechanical Engineering

Its international academic partnerships, designed to help build the curriculum and attract strong founding faculty, include two US institutions, Woods Hole Oceanographic Institution and the University of California at San Diego. Its global research partners who will join in collaborative research working on topics of global significance, include Cornell University, Stanford University, Texas A\&M University and faculty members from Massachusetts Institute of Technology, California Institute of Technology, Michigan State University, Georgia Institute of Technology, Pennsylvania State University, and the University of California at Berkeley.

KAUST is well funded, with a multi-billion dollar endowment. It will enroll both men and women from around the world. The campus, located on the Red Sea at Thuwal, north of Jeddah, is being built in 36 million square meters of land.

\section{United Arab Emirates - Dubai}

Dubai Academic City presents a different model for international academic programs. ${ }^{6}$ Launched in May 2006, it contains "store front" operations of some 32 universities currently. It is a "free zone", meaning that institutions housed there are not required to seek UAE accreditation. It currently serves some 12,000 students on an integrated 25million square foot campus. It is intended to complement an earlier Knowledge Village, launched in 2003, which focuses on training institutes and educational service organizations. Knowledge Village is set up as a profit-making enterprise, where the government-owned company that runs the complex earns money by leasing the buildings to foreign universities. 5

Michigan State University Dubai offers bachelor's degree programs including Computer Engineering and Construction Project Management. It is adding postgraduate degree programs, including a Master of Science in Supply Chain Management. The decision to open operations in Dubai was contingent on several conditions: a requirement that the project be self-sustaining, not use taxpayer money, not drain resources from the main campus, and not utilize foreign investors to underwrite the campus. ${ }^{7}$

Rochester Institute of Technology Dubai is offering master's degree programs including Electrical Engineering, Mechanical Engineering, and Networking and Systems Administration. These are currently offered as part-time study programs in evenings and on weekends. Undergraduate programs in engineering are expected to be offered starting in 2010.

\section{United Arab Emirates - Abu Dhabi}


The Petroleum Institute was created in 2001 to provide engineering education and research in areas of significance to the oil and gas and broader energy industries ${ }^{8}$. It was initiated with major assistance from the Colorado School of Mines, and more recently has also affiliated with the University of Maryland. It offers bachelor's degrees in Chemical, Electrical, Mechanical, Petroleum and Petroleum Geosciences Engineering, and Master of Engineering Degrees in Chemical, Electrical, Mechanical and Petroleum Engineering. It currently has over 1000 undergraduate students and some 50 graduate students.

The New York Institute of Technology ${ }^{9}$ has been offering degree programs in Abu Dhabi since 2005. Its bachelor's degree programs include Computer Science and Information Technology, and its master's degree programs include Computer Science, Electrical and Computer Engineering, and Information, Network and Computer Security. Its classes are coeducational, and follow the same curriculum as its New York campuses. Enrollment is currently 350 , taught by 20 full-time faculty members supplemented by visiting NYIT faculty from New York.

The Masdar Institute of Science and Technology ${ }^{10}$ is the educational component of the Masdar Initiative, a program established in 2006 by the Abu Dhabi government to develop a new economic sector in alternative and sustainable energy. The Masdar Institute is a graduate level institution, offering masters degree programs - and eventually doctoral programs -- in engineering and science disciplines. Current programs are Engineering Systems and Management, Information Technology, Materials Science and Engineering, Mechanical Engineering, and Water and Environment. It is a researchdriven institute being developed with the support and cooperation of Massachusetts Institute of Technology. The Masdar Institute will be located in Masdar City, a \$22million zero carbon emission demonstration city being built at the edge of Abu Dhabi.

As noted above, New York University/Abu Dhabi is being established as a comprehensive liberal arts and sciences campus in Abu Dhabi. With the recent merger of NYU and the Polytechnic University, it is anticipated that engineering programs will eventually be offered at NYU/Abu Dhabi.

\section{American University of ....}

Another vehicle for offering US style education abroad is the American University. These universities are licensed and accredited in the US, but operate abroad. In the Middle East there are several examples currently in operation.

The American University of Beirut was founded in 1866 as a private, independent, nonsectarian institution of higher education. It has grown into a major university with 7000 students on a 73-acre campus overlooking the Mediterranean Sea. Among its programs are Civil and Environmental Engineering, Electrical and Computer Engineering, Mechanical Engineering, and Architecture and Design. 
The American University in Cairo was founded in 1919, and is currently accredited in both Egypt and the US. It serves some 5000 undergraduates from Egypt and from one hundred countries around the world. Its Bachelor of Science degree offerings include Architectural Engineering, Computer Engineering, Computer Science, Construction Engineering, Electronics Engineering, Mechanical Engineering, and Petroleum and Energy Engineering.

The American University of Sharjah was founded in 1997. While consciously based on American institutions of higher education, it is also grounded in Arab culture and part of a larger process of the revitalization of intellectual life in the Middle East. The College of Engineering offers bachelor's degrees in Chemical, Civil, Computer, Electrical and Mechanical Engineering, and in Computer Science. Master's degrees are offered in Engineering Systems Management and in Mechatronics Engineering.

The Lebanese American University, located in Byblos, offers engineering degrees in civil, electrical, computer, industrial and mechanical engineering. Graduate programs are under development.

The American University of Kuwait was established in 2003. Following US models of education, it offers bachelors degrees in Computer Science and in Information Systems.

\section{Issues}

Many of the institutions which have opened branch campuses in the Middle East are suffering from lower than planned enrollments. Where they are supported or subsidized by local governments, the financial pressures of low enrollments are buffered. But in cases where they are full dependent on tuition income, low enrollments provide a less than stable situation.

A branch campus of George Mason University, opened in the UAE emirate of Ras al Khaymah in 2005, became the first American educational venture to collapse. The campus suffered from low enrollments, and was beset by problems revolving around administration, academics and identity. It announced its closing in 2009 when, among other things, its local partner substantially reduced its financial support. ${ }^{11}$

Accreditation is an issue for US higher education institutions offering programs in the Middle East. Some rely on accreditation at a home campus in the US to provide a guarantee of quality, while others seek local accreditation in order to facilitate the employment of graduates in their host countries.

Branch campuses which are established with faculty members from home US campuses generally have a problem in keeping programs staffed with home campus faculty members. The quality of programs may suffer when faculty members who have not been steeped in the home campus culture are employed to fill out faculty numbers . 
There is concern that investments in high-quality undergraduate and graduate education will serve a relatively narrow segment of society in the oil-rich countries. Local students tend to have basic skills issues - poor study habits and motivation, and limited English, math and science skills - and may not qualify for admission. ${ }^{4}$

There is also concern that graduates of these American-style universities may not be connected to the local culture and society in an organic way - perhaps creating a generation of people who cannot speak with their parents. ${ }^{4}$

\section{Conclusion}

US universities are responding to the needs of several countries in the Middle East, especially the oil-rich countries. Several needs are being met, including human capacity building for new directions for the oil-rich countries, and international experience for the US universities.

Institutions which are currently considering involvement in the Gulf region now have the advantage of being able to learn from pioneering efforts, some of which are promising, and others for which the jury is still out. Questions must be asked and honest answers received from everyone. What are the expectations of all stakeholders? How much correlation is there between assessed market needs and planned program offerings? How many of your US-based faculty are willing to invest significant time abroad? How strong is the support of your governing board? How much investment will the university have to make to prepare students for entry into the degree-granting programs? What are the timetables for initiation, roll-out and sustainability of the programs? What are the consequences if those timetables are not met? Who has authority over what? Without adequate transparency, institutional self-awareness, and dedicated leadership, deep international partnerships such as those discussed in this paper can never achieve success in the form of reputable academic programs and sustainable research.

\section{References}

1) Zvika Krieger, "Pouring Money into Culture and Education", Chronicle of Higher Education, 28 March 2008.

2) Tamar Lewin, "U.S. Universities Rush to Set Up Outposts Abroad", New York Times, 10 February 2008.

3) See http://www.qf.edu.qa/

4) Zvika Krueger, "An Academic Building Boom Transforms the Persian Gulf”, Chronicle of Higher Education, 28 March 2008.

5) See http://www.kaust.edu.sa/ 
6) See http://www.diacedu.ae/

7) Karin Fischer, "How the Deal Was Done: Michigan State in Dubai", Chronicle of Higher Education, 28 March 2008.

8) See http://www.pi.ac.ae/

9) See http://www.nyit.edu

10) See http://www.mist.ac.ae/

11) Andrew Mills, “Failure of George Mason U.'s Persian Gulf Campus Sparks Concern About Overseas Ventures", Chronicle of Higher Education, 6 March 2009. 